\title{
APPLICATION OF Nd-YAG LASER TREATMENT FOR ORAL LEUKOPLAKIA
}

\author{
Hristina Lalabonova, Stefka Peycheva, P. Petrov. \\ Department of Maxillofacial Surgery, Faculty of Dental Medicine, \\ Medical University - Plovdiv, Bulgaria
}

\begin{abstract}
High energy lasers are used as an alternative to conventional surgery for treatment of oral leukoplakia.

The purpuse of this study is to monitor the effectiveness of Nd-YAG laser as treatment for oral leukoplakia. Seventeen patients were followed-up with oral leukoplakia for the period 2005-2011. NdYAG laser was used with following parameters: $\lambda$ $1064 \mathrm{~nm}, 10-15 \mathrm{~W}, \mathrm{~T} 40-70$ sec. Early postoperative results were monitored considering criteria pain, redness, swelling each $1,3,7$ days. The effect from the treatment was determined by recording the changes in size of the lesions each 1 , 2, 3 months. The results which reflect effectiveness of treatment within the observed period showed that twelve patients were complete respondents, two responded partially, and three did not respond. The treatment of oral leukoplakia through the application of Nd-YAG laser is characterized with good therapeutic effect and smooth postoperative period, without significant pain and discomfort, making it appropriate clinical solution.
\end{abstract} treatment.

Key words: oral leukoplakia, Nd-YAG laser,

\section{INTRODUCTION}

Cases of cancer in humans tend to become more frequent, while reasons for this are referred to a number of exogenous and endogenous factors.

Genetic damage in the epithelium accumulates during the process of carcinogenesis and leads to the loss of cell cycle regulation and the emergence of uncontrolled reproduction. (4)

Oral preneoplasia is damage in the epithelium, progress of which continues for months or for years and in some cases it turns into cancer. (2)
Leukoplakia is a white plaque or patch on the mucous membrane having a potential risk for malignancy. This is the most common preneoplastic oral lesion. $(9,11)$

The etiology and pathogenesis of oral leukoplakia are not fully known, there are no specific histological findings. There are risk factors involved in the disease progress. They are most commonly related to tobacco use, consumption of alcohol and the HPV infection. $(8,9)$

Diagnosis of oral leukoplakia is mainly carried out through a direct visual inspection, vital dye staining is also used as well as stomatoscopy and spectroscopy, exfoliative cytodiagnosis. The histological examination of biobsy material, combined with the modern means of immunohistochemistry may allow early registration of changes in the tissues, before the clinical expression of the ongoing changes at a cellular level. $(1,9)$

Approach in the treatment of oral leukoplakia involves removal of risk factors, impact on the lesion and follow-up of the deseased. Depending on the clinical and histological features, topically or systemically are being applied medications, surgical and electrosurgical excision procedures followed by plastics, cryotherapy, low or high energy lasers. (4, $5,6,9)$

High energy lasers are used as an alternative to surgical treatment. $(5,7)$

Carbon dioxide (CO2) laser has a wavelength of $10600 \mathrm{~nm}$, it is well absorbed by intra and extracellular fluids, it quickly reaches temperature and evaporates the target tissues and the surrounding area of thermal necrosis. It is used with a focused wave mode for axcision of the lesions, and with a defocused wave mode for evaporating.

Diod lasers are used in different modes for excision of the lesions.

Nd-YAG laser has been introduced long ago in 
medicine (1973), it has great energy and penetrates deep into tissues. It is used for ablation of oral leukoplakia with very good subsequent results. More pronounced thermal effect and pain during the procedure, requiring anesthesia, should be considered as negative aspects of the treatment with this type of laser. $(7,10)$

The Purpose of this study is to evaluate the efficacy of the treatment with Nd-YAG laser on patients with oral leukoplakia.

\section{MATERIAL}

Seventeen patients were followed-up with oral leukoplakia for the period 2005-2011, they were treated in the Department of Maxillofacial Surgery at St. George University Hospital in Plovdiv, Nd-YAG laser treatment was applied.

\section{METHODS}

Nd-YAG laser was used with the following parameters:
$\lambda \quad 1064 \mathrm{~nm}$
W $10-15 \mathrm{~W}$
T $\quad 40-70 \mathrm{sec}$

The laser was applied for evaporation of tissues, while the impact was on an area of $1 \mathrm{~cm}^{2}$ or on a part of this area. In cases with larger lesions the areas out of this range were treated in 7 to 10 days. Same manipulation may be repeated on the same area but not earlier than 20 days. treatment.

Size of the lesions was defined prior to

Early postoperative results and late effects of the treatment were monitored.

The early postoperative results were reported at 1, 3 and 7 days by rating the following criteria:

1. pain - measured on a visual analog scale (VAS) with numbers from 0 to 10 , where 0 indicates absence of any pain and 10 indicates appalling and unbearable pain.

2. redness - presence or absence of redness in the area of the lesion is reported.

3. swelling - presence or absence of swelling in the treated area is reported.

The late effects of the treatment were monitored on the first, second and third month after the impact, considering the criteria change in size of the lesion compared to the initially measured.

\section{RESULTS}

Early postoperative results:

1. pain - it is ascertained that the studied patients experienced slight irritation to mild discomfort one day after the laser procedure. In most patients these feelings were gone by the third day and in the rest of the patients - by the seventh day.

2. redness - all patients had redness in the treated area during the first postoperative day, this redness gradually faded by the seventh day.

3. swelling - none of the studied group revealed swelling in the tissues in the treated area.

Late effects of the treatment:

- First month - the lesion disappears in 12 patients. Pin-point residues were registered in 5 patients.

- Second month - there are no recurrence registered by those 12 . As for the 5 cases with the pin-point residues: 2 of them showed no change, and in the other 3 there was an increase in the area by comparison with the initial size registered in the first month.

- Third month - no recurrence by the twelve, no changes by the two with the pin-point residues. The other 3 restored the initial size of the lesions. All three of the diseased continue to smoke more than 20 cigarettes a day.

The results which reflect the effectiveness of the treatment within the observed period showed that twelve patients were complete respondents, two responded partially, and three did not respond the treatment. Their risk factor of tobacco use was not removed.

\section{CONCLUSION}

Considering the results obtained it can be concluded that the treatment of oral leukoplakia through the application of Nd-YAG laser is characterized with good therapeutic effect and smooth postoperative period with no significant pain and discomfort, making it an appropriate solution in complex treatment of the disease. 


\section{REFERENCES:}

1. Lalabonova Hr, Firkova E. Lasers in Dentistry. Physical medicine, rehabilitation, health. 2006, 4, 4-9. [in Bulgarian]

2. Banoczy J, Csiba A. Comparative study of the clinical picture and histopathologic structure of oral leucoplakia. Cancer. 1972 May;29(5): 1230-1234. [PubMed]

3. Bokor-Bratic M. The prevalence of precancerous oral lesions. Oral leukoplakia. Archive of Oncology. 2000; 8(4):169-70.

4. Chiesa F, Tradati N, Grigolato R, Boracchi P, Biganzoli E, Crose N, et all. Randomized trial of fenretinide (4-HPR) to prevent recurrences, new localizations and carcinomas in patients operated on for oral leukoplakia: Long-term results. Int $J$ Cancer. 2005 Jul 1;115(4)625629. [PubMed] [CrossRef]

5. Gillenwater A, Papadimitrakopoulou V, Richards-Kortum R. Oral
Premalignancy: New Methods of Detection and Treatment. Curr Oncol Repor. 2006 Mar;8(2):146-154. [PubMed]

6. Ishii J, Fujita K, Komori T. Laser surgery as a treatment for oral leukoplakia. Oral Oncol. 2003 Dec; 39(8)759-769. [PubMed] [CrossRef]

7. Kademani D, Dierks E. Surgical Management of Oral and Mucosal Dysplasias: The Case for Surgical Excision. J Oral Maxillofac Surg. 2007 Feb;65(2):287-292. [PubMed]

[CrossRef]

8. Novakovic D, Rickert S, Blitzer A. Office-based laser treatment of oral premalignant lesions. Operative Techniques in Otolaryngology. 2011, 22, 159-164.

9. Roed-Peterson B, Gupta PC, Pindborg JJ, Sing B. Association between oral leukoplakia and sex, age, and tobacco habits. Bull World Health Organ. 1972; 47(1):13-19. [PubMed]

10. van der Waal I. Potentially malignant disorders of the oral and oropharyngeal mucosa; terminology, classification and present concepts of management. Oral Oncol. 2009 AprMay;45(4-5):317-323. [PubMed] [CrossRef]

11. Vivek V, Jayasree RS, Balan A, Sreelatha KT, Gupta AK. Three-year follow-up of oral leukoplakia after neodymium:yttrium aluminum garnet (Nd:YAG) laser surgery. Lasers Med Sci. 2008 Oct;23(4):375-379. [PubMed] [CrossRef]

12. Warnakulasuriya S, Johnson N, van der Waal I. Nomenclature and classification of potentially malignant disorders of the oral mucosa. $J$ Oral Pathol Med. 2007 Nov;36(10):575-80. [PubMed] [CrossRef]

\section{Correspondence address:}

Assoc. prof. Hristina Lalabonova,

Department of Maxillofacial Surgery, Faculty of Dental Medicine, 11, Opalchenska Str., 4000 Plovdiv, Bulgaria tel.: $+359 / 888608406$ e-mail: lalabonova@abv.bg 